DOI: $10.5846 /$ stxb201301290184

陶否, 褚贵新, 刘涛, 唐诚, 李俊华, 梁永超. 有机肥替代部分化肥对长期连作棉田产量、土壤微生物数量及酶活性的影响.生态学报, 2014,34 (21) :6137-6146.

Tao L, Chu G X, Liu T, Tang C Li J H, Liang Y C.Impacts of organic manure partial substitution for chemical fertilizer on cotton yield, soil microbial community and enzyme activities in mono-cropping system in drip irrigation condition.Acta Ecologica Sinica, 2014,34(21) :6137-6146.

\title{
有机肥替代部分化肥对长期连作棉田产量、 土壤微生物数量及酶活性的影响
}

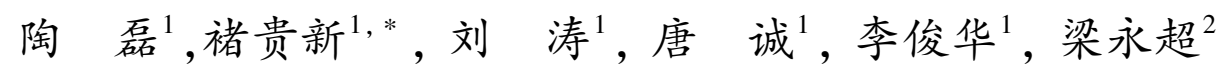

(1. 石河子大学农学院资源与环境科学系, 新疆生产建设兵团绿洲生态农业重点实验室, 石河子 832003;

2. 中国农业科学院农业资源与农业区划研究所, 农业部作物营养与施肥重点实验室, 北京 100081)

摘要: 施用有机物是作物增产、增加土壤有机质和改善土壤生物学性状的有效措施。在大田滴灌条件下,采用土壤酶学和微生 物平板培养方法, 研究了常规施肥 (CF) 减量 20\%-40\%, 配施 $3000 、 6000 \mathrm{~kg} / \mathrm{hm}^{2}$ 有机类肥料对棉花产量、土壤微生物数量及土 壤酶活性的影响。结果表明: 降低 CF 用量 20\%-40\%情况下, 滴灌棉田配施 $3000,6000 \mathrm{~kg} / \mathrm{hm}^{2}$ 的有机类肥料可获得与 CF 处理 相持平的产量 ( $\left.4945-4978 \mathrm{~kg} / \mathrm{hm}^{2}\right)$, 有机肥和生物有机肥配施处理间的棉花产量差异不显著 $(P<0.05)$ 。细菌、放线菌和假单 胞杆菌数量均随有机肥用量的增加而升高, 不同类有机肥配施间表现为 $\mathrm{OF}+\mathrm{BF}>\mathrm{BF}>\mathrm{OF}$; 真菌数量则随有机肥施量升高而降 低,其中 $\mathrm{OF}+\mathrm{BF}$ 配施处理最为显著。有机无机肥配施显著提高了土壤酶活性, $80 \% \mathrm{CF}$ 和 $60 \% \mathrm{CF}$ 与有机肥配施处理土壤碱性 磷酸酶、苂光素二乙酸酥酶 (FDA)、 $\beta$-葡萄糖苷酶和脱氢酶的活性比 CF 处理分别升高了 $3.8 \% 、 17 \% 、 18 \% 、 55 \%$ 和 $10.1 \% 、 19 \%$ 、 $20 \% 、 60 \%$, 不同类型有机肥对土壤酶活性影响差异不显著。土壤细菌/真菌比、土壤放线菌/真菌和假单胞杆菌/真菌比均随有 机肥施量的增加而升高, 施用化肥或有机肥均显著降低了假单胞杆菌/细菌比。细菌、放线菌和假单胞杆菌数量与土壤脱氢酶、 $\beta$-葡萄糖苷酶、碱性磷酸酯酶和苂光素二乙酸酯酶活性均呈显著或极显著正相关, 真菌数量与 4 种酶活性呈负相关。CF 减量 $20 \%$ - $40 \%$ 配施以 $3000 、 6000 \mathrm{~kg} / \mathrm{hm}^{2}$ 有机肥不仅不会导致棉花减产, 而且对提高土壤酶活性、调节土壤细菌、真菌、放线菌群落 组成结构,改善北疆绿洲滴灌棉田土壤生物学性状有显著作用。

关键词: 棉花; 土壤酶活性; 土壤微生物; 生物有机肥

\section{Impacts of organic manure partial substitution for chemical fertilizer on cotton yield, soil microbial community and enzyme activities in mono-cropping system in drip irrigation condition}

TAO Lei ${ }^{1}$, CHU Guixin ${ }^{1, *}$, LIU Tao ${ }^{1}$, TANG Cheng ${ }^{1}$, LI Junhua ${ }^{1}$, LIANG Yongchao ${ }^{2}$

1 Department of Resources and Environmental Science, College of Agriculture, The Key Laboratory of Oasis Eco-agriculture of the Xinjiang Production and Construction Corps, Shihezi University, Shihezi 832003, China

2 Key Laboratory of Crop Nutrition and Fertilization, Ministry of Agriculture, Institute of Agricultural Resources and Regional Planning, China Academy of Agricultural Sciences, Beijing 100081, China

Abstract: Organic fertilizer application is an effective approach to enhancing soil organic matter, soil biological activity as
well as crop yield in agriculture. In the present research, a two-year field experiment was established to study the impacts of
combined use of organic fertilizer with chemical fertilizer ( $\mathrm{CF}$ ) on cotton yield, soil microbial biomass, soil enzyme

基金项目:农业部行业项目资助(201103004)

收稿日期: 2013-01-29; 网络出版日期:2014-03- 13

*通讯作者 Corresponding author.E-mail: chuguixinshzu@ 163.com 
activities and soil microbial community structural composition in drip-irrigation condition in northern Xinjiang. Compared with CK, $100 \%$ chemical fertilizer treatment $\left(300 \mathrm{~kg} \mathrm{~N} / \mathrm{hm}^{2}, 90 \mathrm{~kg} \mathrm{P} \mathrm{O}_{5} / \mathrm{hm}^{2}, 60 \mathrm{~kg} \mathrm{~K} \mathrm{O} / \mathrm{hm}^{2}\right.$ ) or treatments of organic manure at different rates combined with chemical fertilizer significantly increased $(P<0.05)$ cotton yield. With chemical fertilizer or organic manure supply, cotton yield could be reached up to $4945-4978 \mathrm{~kg} / \mathrm{hm}{ }^{2}$, however, there was no statistical difference $(P<0.05)$ among $100 \%$ CF fertilization and treatments with $20 \%$ to $40 \%$ chemical fertilizer substituted by $3000-6000 \mathrm{~kg} / \mathrm{hm}^{2}$ organic fertilizer. The number of soil bacteria, actinomycetes as well as pseudomonas significantly increased with increasing amendment rate of organic manure, but the number of soil fungi decreased with organic fertilizer rates increasing. For instance, the number of soil bacteria increased by $13 \%-41 \%$ in the treatments of organic manure at different rates combined with $\mathrm{CF}$ than in the treatment with $100 \% \mathrm{CF}$, whereas, the number of soil fungi in the treatment with $100 \% \mathrm{CF}$ fertilizer is $1.4-1.6$ times higher than that in the treatment with organic manure combined with $\mathrm{CF}$ at budding stage of cotton. Organic fertilizer application significantly enhanced $(P<0.05)$ soil enzyme activities. Compared with the treatment with $100 \% \mathrm{CF}$ supply, soil enzyme activities of alkaline phosphatase, fluorescein acetate esterase, $\beta$ glucosidase and dehydrogenase increased by $3.8 \%, 17 \%, 18 \%$ and $55 \%$ in the treatments with $80 \%$ CF combined with $3000 \mathrm{~kg} / \mathrm{hm}^{2}$ organic manure, and increased by $10.1 \%, 19 \%, 20 \%$, and $60 \%$ in the treatments with $60 \% \mathrm{CF}$ fertilizer combined with $6000 \mathrm{~kg} / \mathrm{hm}^{2}$ organic manure (BF-organic), respectively. The ratios of soil bacteria/fungi, soil actinomycetes/fungi and pseudomonas/fungi increased with increasing application rate of organic manure, but pseudomonas/bacteria ratio markedly reduced in the treatment with $100 \mathrm{CF}$ or organic fertilizer supply. A significant positive correlation $(P<0.05)$ was observed between the number of soil bacteria, actinomycetes and pseudomonas was significantly positively correlated with the activity of soil enzymes including dehydrogenase, $\beta$-glucosidase, alkaline phosphatase and fluorescein acetate esterase, respectively. However, an obvious negative correlation was observed between soil fungi number and the activity of soil enzymes such as dehydrogenase, $\beta$-glucosidase, alkaline phosphatase and fluorescein acetate esterase. Our conclusion is that $20 \%-40 \%$ of total chemical fertilizer application rate can be substituted by $3000-6000$ $\mathrm{kg} / \mathrm{hm}^{2}$ organic fertilizer with no cotton yield decrease. Moreover, organic fertilizer addition addition plays a significant role in increasing soil enzyme activities, regulating soil microbial community structural composition as well as improving soil biological properties in cotton mono-cropping system under drip-irrigation condition in northern Xinjiang.

Key Words : cotton; soil enzyme activities; soil microorganism; organic manure

施肥是作物增产最有效的途径。据联合国粮农 组织 (FAO) 统计, 肥料对粮食作物的贡献率在 $30 \%-50 \%{ }^{[1]}$, 我国化肥长期定位试验网数据统计 也表明化肥对我国粮食产量的贡献率为 $40.8 \%$ 。 有机无机肥配施一直是我国农业施肥的指导方针, 然而近 50 年来, 化学肥料的施用量逐年增加, 与之 对应的是有机肥施用量急剧下降。沈其荣等 ${ }^{[3]}$ 研究 表明,在 $1960 、 1980 、 2000 、 2010$ 年我国有机肥施用 量占总施肥量的 $80 \% 、 60 \% 、 30 \% 、 10 \%$ 。长期单施和 过量施用化学肥料已造成土壤有机质含量降低、理 化性状恶化 ${ }^{[4]}$,肥料利用率下降 ${ }^{[5]}$ 和土壤微生物性 状发生变化 ${ }^{[6]}$ 。化学肥料不合理和过度施用的负面 影响已经引起政府和科学界的重视,我国政府提出 “引导农民合理施肥,鼓励增施有机肥”, 从农业废弃
物高效利用和维护农田地力的角度出发, 有机无机 配施将是我国今后肥料施用发展的必然趋势 ${ }^{[7]}$ 。国 内长期定位施肥实验表明,有机无机肥配施不但可 降低土壤容重, 增加总孔隙度和物理性粘粒含量, 改 善土壤理化性状 ${ }^{[8]}$, 而且可显著提升土壤物质生产 性能与地力 ${ }^{[9-10]}$

已有研究表明,利用有机肥或功能型的生物有 机肥不仅可明显提高土壤生物活性 ${ }^{[11-12]}$, 而且在调 控健康土壤微生物区系和防治土传病害方面有着突 出作用 ${ }^{[13-14]}$ 。利用有机废弃物变污染源为养分资 源, 探究科学合理的有机肥与无机肥配施比例, 形成 精制有机肥或功能型生物有机肥, 不仅可达到减肥 增效和提高养分资源高效利用,也关乎到以有机促 无机提高化肥利用率, 构建健康土壤微生物区系, 减 
轻土传病害 ${ }^{[15]}$,进而提高土壤可持续利用等关键问 题。棉花是新疆农业的支柱产业, 受经济利益驱动 北疆棉区长期进行棉花连作, 致使棉田土壤微环境 发生了改变 ${ }^{[16]}$, 特别是近 30 余年的连作致使棉田 土传病害频发。石否岩 ${ }^{[17]}$ 研究认为这与棉田土壤 微生物数量和土壤酶活性有关系, 是绿洲滴灌土壤 在长期连作过程中致病性真菌的累积所致。本研究 对有机肥部分替代化肥对棉花产量的效应以及化肥 与有机肥或生物有机肥不同配比对棉田土壤微生物 性状的影响进行了研究, 旨在比较有机肥、生物有机 肥部分替代化学对绿洲农田生产力、土壤微生物群 落结构及土壤生物学性状的影响, 所得结果可为滴 灌条件下长期连作棉田的土壤微生物区系构建和提 高绿洲农田生产力及养分资源高效利用提供参考。

\section{1 材料与方法}

\section{1 试验区概况与实验设计}

试验区基本情况: 试验田位于石河子大学农试 场 ( E $84^{\circ} 58^{\prime}-86^{\circ} 24^{\prime}, \mathrm{N} 43^{\circ} 26^{\prime}-45^{\circ} 20^{\prime}$ ), 年平均 气温 $7.5-8.2^{\circ} \mathrm{C}$, 年降雨量 $180-270 \mathrm{~mm}$, 年蒸发量 1000-1500 mm。供试土壤属灌耕灰漠土(灌淤旱耕 人为土, Calcaric Fluvisals), 施肥处理前 $0-20 \mathrm{~cm}$ 土 壤基础有机质含量 $23.6 \mathrm{~g} / \mathrm{kg}$; 全氮 $0.95 \mathrm{~g} / \mathrm{kg}$; 全磷 $0.3 \mathrm{~g} / \mathrm{kg}$; 碱解氮 $88.6 \mathrm{mg} / \mathrm{kg}$; 速效磷 $23.4 \mathrm{mg} / \mathrm{kg}$; 速 效钾 $136 \mathrm{mg} / \mathrm{kg} ; \mathrm{pH}$ 值 8.1 。

试验设置 8 个处理: (1) CK (不施肥); (2) CF $\left(300 \mathrm{~kg} \cdot \mathrm{N} / \mathrm{hm}^{2} ; 90 \mathrm{~kg} \cdot \mathrm{P}_{2} \mathrm{O}_{5} / \mathrm{hm}^{2} ; 60 \mathrm{~kg} \cdot \mathrm{K}_{2} \mathrm{O} /\right.$ $\left.\mathrm{hm}^{2}\right)$; (3) $80 \% \mathrm{CF}+\mathrm{OF}_{1}(80 \% \mathrm{CF}+$ 有机肥 $3000 \mathrm{~kg} /$ $\left.\mathrm{hm}^{2}\right)$; (4) $60 \% \mathrm{CF}+\mathrm{OF}_{2}(60 \% \mathrm{CF}+$ 有机肥 $6000 \mathrm{~kg} /$ $\left.\mathrm{hm}^{2}\right) ;(5) 80 \% \mathrm{CF}+\mathrm{BF}_{1}(80 \% \mathrm{CF}+$ 生物有机肥 3000 $\left.\mathrm{kg} / \mathrm{hm}^{2}\right) ;(6) 60 \% \mathrm{CF}+\mathrm{BF}_{2}(60 \% \mathrm{CF}+$ 生物有机肥 $\left.6000 \mathrm{~kg} / \mathrm{hm}^{2}\right)$; (7) $80 \% \mathrm{CF}+\mathrm{OF}_{3}+\mathrm{BF}_{3}(80 \% \mathrm{CF}+$ 有机 肥 $2250 \mathrm{~kg} / \mathrm{hm}^{2}+$ 生物有机肥 $\left.750 \mathrm{~kg} / \mathrm{hm}^{2}\right)$; (8) $60 \%$ $\mathrm{CF}+\mathrm{OF}_{4}+\mathrm{BF}_{4}\left(60 \% \mathrm{CF}+\right.$ 有机肥 $4500 \mathrm{~kg} / \mathrm{hm}^{2}+$ 生物有 机肥 $\left.1500 \mathrm{~kg} / \mathrm{hm}^{2}\right)$ 。每个小区面积 $90 \mathrm{~m}^{2}$, 各处理重 复 3 次, 随机排列分布。化学肥料为尿素 $(N=$ $46 \%)$ 、磷酸钾铵 $\left(\mathrm{P}_{2} \mathrm{O}_{5}=24 \%\right)$ 、磷酸二氢钾 $\left(\mathrm{K}_{2} \mathrm{O}=\right.$ $31.8 \%$ ); 有机肥为腐熟牛粪, 有机质含量 $24.8 \%$; 生 物有机肥为江苏新天地生物肥料有限公司生产的 “BIO”生物有机肥, 有机质含量为 $29.7 \%$, 抗病菌种 有效活菌数 $\geqslant 0.5$ 亿 $\mathrm{g}$, 氮磷钾 $\geqslant 6 \%$ 。有机肥和生
物有机肥做基肥播前一次施人,化学肥料是在棉花 生育期根据其需肥特性按比例分为 8 次随水滴施。

\section{2 取样及样品处理}

本实验分别于 2011 年 7 月 18 日 (棉花蕾期) 和 8 月 21 日 (棉花铃期) 两次在各处理采集供分析用 的土壤样品,采样深度为 $0-20 \mathrm{~cm}$ 耕层土壤, 每小 区采 3 个样品作为重复, 每个样品均为多点混合, 剔 除砾石和植物残根, 过 $2 \mathrm{~mm}$ 篮。7 月 18 日土样立 刻进行土壤微生物培养, 8 月 21 日土样分成两部分, 一部分立刻进行微生物培养, 另一部分土样置于 4 ${ }^{\circ} \mathrm{C}$ 冰箱内保存, 1 周内测定土壤酶活性。

\section{3 测定方法}

\subsection{1 土壤微生物平板培养}

细菌: 培养基参考 Perez-Piqueres ${ }^{[18]}$, 刮刀法接 种稀释 $10^{-5}$ 土壤悬浮液于琼脂表面, $29^{\circ} \mathrm{C}$ 培养 $36 \mathrm{~h}$ 计数; 真菌: 培养基参考 Perez-Piqueres ${ }^{[18]}$, 刮刀法接 种稀释 $10^{-2}$ 土壤悬浮液于琼脂表面, $29{ }^{\circ} \mathrm{C}$ 培养 $84 \mathrm{~h}$ 计数; 放线菌: 培养基参考 Clive ${ }^{[19]}$, 刮刀法接种稀释 $10^{-3}$ 土壤悬浮液于琼脂表面, $29^{\circ} \mathrm{C}$ 培养 $108 \mathrm{~h}$ 计数; 假单胞杆菌: 培养基参考 William ${ }^{[20]}$, 刮刀法接种稀 释 $10^{-4}$ 土壤悬浮液于琼脂表面, $29{ }^{\circ} \mathrm{C}$ 培养 $48 \mathrm{~h}$ 计数。

\subsection{2 土壤酶活性测定}

测定方法参考《土壤与环境微生物研究法》 ${ }^{[21]}$ : 土壤脱氢酶用 TTC 还原比色法,用单位时间内单位 土壤三苯基甲兟 (TPF) 生成量表示; 碱性磷酸酶用 苯磷酸二钠法比色法, 以每百克土的酚毫克数表示; $\beta$-葡萄糖苷酶采用 $\beta$-葡萄糖苷-苯二酚滴定法, 结果 以 $1 \mathrm{~g}$ 土壤 $1 \mathrm{~h}$ 生成对硝基酚的量 $(\mu \mathrm{g})$ 表示; 苂光素 二乙酸酯水解酶 (FDA) 采用比色法, 以单位土壤在 单位时间内生成的苂光素量 $(\mu \mathrm{g})$ 表示。

\section{4 数据分析}

用 SPSS 17.0 进行统计分析, 单因素方差分析 (One way ANOVA), 比较不同处理间差异显著性 $(P=0.05)$ 和 Duncan 新复极差法然后经过 $t$ 检验 $(P<0.05)$, 微生物数量与酶活性关系用 Pearson 相 关系数分析, 绘图由 GraphPad Prim5 软件完成。

\section{2 结果与分析}

2.1 有机无机肥配施对棉花产量的影响 由图 1 可知,相较于 $\mathrm{CK}, \mathrm{OF} 、 \mathrm{BF} 、 \mathrm{OF}+\mathrm{BF}$ 配施等 


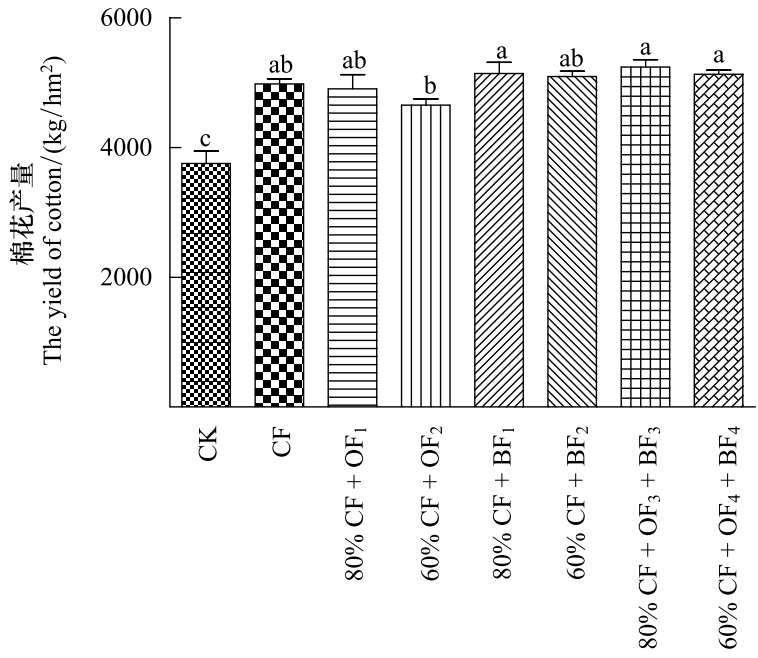

图 1 有机无机肥配施对棉花产量的影响

Fig.1 The response of cotton yield to treatments of manure combined with chemical fertilizers

$\mathrm{CK}$ : 不施肥对照; $\mathrm{CF}$ : 灌耕灰漠土 (灌淤旱耕人为土) Conventional fertilization; $80 \% \mathrm{CF}+\mathrm{OF}_{1}: 80 \% \mathrm{CF}+$ 有机肥 $3000 \mathrm{~kg} /$ $\mathrm{hm}^{2} ; 60 \% \mathrm{CF}+\mathrm{OF}_{2}: 60 \% \mathrm{CF}+$ 有机肥 $6000 \mathrm{~kg} / \mathrm{hm}^{2} ; 80 \% \mathrm{CF}+\mathrm{BF}_{1}$ : $80 \% \mathrm{CF}+$ 生物有机肥 $3000 \mathrm{~kg} / \mathrm{hm}^{2} ; 60 \% \mathrm{CF}+\mathrm{BF}_{2}: 60 \% \mathrm{CF}+$ 生物 有机肥 $6000 \mathrm{~kg} / \mathrm{hm}^{2} ; 80 \% \mathrm{CF}+\mathrm{OF}_{3}+\mathrm{BF}_{3}: 80 \% \mathrm{CF}+$ 有机肥 2250 $\mathrm{kg} / \mathrm{hm}^{2}+$ 生物有机肥 $750 \mathrm{~kg} / \mathrm{hm}^{2} ; 60 \% \mathrm{CF}+\mathrm{OF}_{4}+\mathrm{BF}_{4}: 60 \% \mathrm{CF}+$ 有机肥 $4500 \mathrm{~kg} / \mathrm{hm}^{2}+$ 生物有机肥 $1500 \mathrm{~kg} / \mathrm{hm}^{2}$

量化学肥料对棉花产量增幅分别为 $24 \%-31 \%$ 、 $34 \%-37 \%$ 和 $37 \%-40 \%$; 与 $\mathrm{CF}$ 处理相比, 仅 60\% $\mathrm{CF}+\mathrm{OF}_{2}$ 处理的棉花产量有所下降,其它有机无机肥 配施处理的产量略高于或接近 CF, 但差异不明显
$(P<0.05)$ 。表明在减少化学肥料用量的 $20 \%-$ $40 \%$ 的条件下, 配施 $3000,6000 \mathrm{~kg} / \mathrm{hm}^{2}$ 的有机肥或 生物有机肥, 能完全满足棉花生长和稳定产量的养 分需求; 有机无机肥配施处理间整体表现 $80 \% \mathrm{CF}+$ $(\mathrm{OF} / \mathrm{BF})>60 \% \mathrm{CF}+(\mathrm{OF} / \mathrm{BF})$, 其中 $80 \% \mathrm{CF}+\mathrm{OF}_{3}+$ $\mathrm{BF}_{3}$ 的产量最高, 等量化学肥料配施有机肥与配施生 物有机肥处理间无明显差异。

\section{2 有机无机肥配施对土壤微生物数量的影响}

平板稀释培养结果显示 (表 1), 不同施肥条件、 棉花的不同生育期,棉田土壤细菌、放线菌和假单胞 杆菌与真菌数量变化不一致。其中细菌数量变化趋 势随着有机肥施人量的增加而增加, 各施肥处理蕾 期细菌数量大于铃期; 有机配施处理细菌数量在蕾 期和铃期分别是 CF 的 $1.15-1.69$ 和 $1.13-1.61$ 倍; 有机配施处理间蕾期和铃期细菌数量均表现为 $\mathrm{OF}+\mathrm{BF}>\mathrm{BF}>\mathrm{OF}$, 同类有机肥配施不等量化学肥料差 异不显著。相较 $\mathrm{CF}$,有机无机肥配施处理显著增加 土壤放线菌数量, 增幅为蕾期 $7 \%-17 \%$ 和铃期 $10 \%$ $-14 \%$,蕾期和铃期相同处理间放线菌变化不显著; 有机配施处理间无明显差异。假单胞杆菌数量变化 与细菌有着相似的趋势。真菌数量变化趋势则随着 施人化学肥料量的增加而升高, 蕾期和铃期均有 $\mathrm{CF}$ $>80 \% \mathrm{CF}>60 \% \mathrm{CF}>\mathrm{CK}$, 铃期大于蕾期真菌数量 ; 有机 配施处理间真菌数量在蕾期无差异,而铃期则有 $\mathrm{OF}$ $>\mathrm{BF}>\mathrm{OF}+\mathrm{BF}$,但差异不明显。

\section{表 1 有机无机肥配施对土壤细菌、真菌、放线菌和假单胞杆菌数量的影响}

Table 1 The quantities of soil bacteria, fungi, actinomycetes and pseudomonas responsive to treatments of organic manure and chemical fertilizer

\begin{tabular}{|c|c|c|c|c|c|c|c|c|c|c|}
\hline \multirow{2}{*}{$\begin{array}{l}\text { 处理 } \\
\text { Treatment }\end{array}$} & \multicolumn{2}{|c|}{$\begin{array}{c}\text { 细菌 Bacteria/ } \\
\left.\left(\times 10^{7} \mathrm{cfu} / \mathrm{g} \text { (干土 }\right)\right)\end{array}$} & \multicolumn{2}{|c|}{$\begin{array}{c}\text { 真菌 Fungi/ } \\
\left(\times 10^{4} \mathrm{cfu} / \mathrm{g} \text { (干土 }\right)\end{array}$} & \multicolumn{2}{|c|}{$\begin{array}{c}\text { 放线菌 Actinomycetes/ } \\
\left.\left(\times 10^{5} \mathrm{cfu} / \mathrm{g} \text { (干土 }\right)\right)\end{array}$} & \multicolumn{2}{|c|}{$\begin{array}{c}\text { 假单胞杆菌 Pseudomonas/ } \\
\left.\left(\times 10^{6} \mathrm{cfu} / \mathrm{g} \text { (干土 }\right)\right)\end{array}$} & \multicolumn{2}{|c|}{$\begin{array}{l}\text { 微生物总计 Total/ } \\
\left.\left(\times 10^{4} \mathrm{cfu} / \mathrm{g} \text { (干土 }\right)\right)\end{array}$} \\
\hline & $\begin{array}{l}\text { 蕾期 } \\
\text { Bud stage }\end{array}$ & $\begin{array}{c}\text { 铃期 } \\
\text { Boll stage }\end{array}$ & $\begin{array}{c}\text { 蕾期 } \\
\text { Bud stage }\end{array}$ & $\begin{array}{c}\text { 铃期 } \\
\text { Boll stage }\end{array}$ & $\begin{array}{c}\text { 蕾期 } \\
\text { Bud stage }\end{array}$ & $\begin{array}{c}\text { 铃期 } \\
\text { Boll stage }\end{array}$ & $\begin{array}{c}\text { 蕾期 } \\
\text { Bud stage }\end{array}$ & $\begin{array}{c}\text { 铃期 } \\
\text { Boll stage }\end{array}$ & $\begin{array}{l}\text { 蕾期 } \\
\text { Bud stage }\end{array}$ & $\begin{array}{l}\text { 铃期 } \\
\text { Boll stage }\end{array}$ \\
\hline CK & $1.12 \mathrm{f}$ & $1.01 \mathrm{e}$ & $1.97 \mathrm{c}$ & $2.54 \mathrm{de}$ & $2.59 \mathrm{c}$ & $2.68 \mathrm{~d}$ & $4.86 \mathrm{a}$ & $4.42 \mathrm{c}$ & $1125 \mathrm{f}$ & $1039 \mathrm{f}$ \\
\hline $\mathrm{CF}$ & $1.29 \mathrm{e}$ & $1.16 \mathrm{e}$ & $4.07 \mathrm{a}$ & $5.56 \mathrm{a}$ & $3.18 \mathrm{~b}$ & $3.06 \mathrm{~cd}$ & $4.95 \mathrm{ab}$ & $4.41 \mathrm{c}$ & $1321 \mathrm{e}$ & $1193 \mathrm{e}$ \\
\hline $80 \% \mathrm{CF}+\mathrm{OF}_{1}$ & $1.59 \mathrm{~d}$ & $1.33 \mathrm{c}$ & $2.81 \mathrm{~b}$ & $3.89 \mathrm{~b}$ & $3.41 \mathrm{ab}$ & $3.28 \mathrm{bc}$ & $5.35 b$ & $5.05 b$ & $1628 \mathrm{~d}$ & $1365 \mathrm{c}$ \\
\hline $60 \% \mathrm{CF}+\mathrm{OF}_{2}$ & $1.48 \mathrm{~d}$ & $1.31 \mathrm{~cd}$ & $2.87 \mathrm{~b}$ & $3.58 \mathrm{bc}$ & $3.82 \mathrm{a}$ & 3.63ab & $5.39 \mathrm{~b}$ & $5.29 \mathrm{ab}$ & $1524 d$ & $1346 \mathrm{~cd}$ \\
\hline $80 \% \mathrm{CF}+\mathrm{BF}_{1}$ & $1.77 \mathrm{c}$ & $1.59 \mathrm{~b}$ & $2.48 \mathrm{~b}$ & $3.37 \mathrm{bc}$ & $3.64 \mathrm{a}$ & $3.77 \mathrm{a}$ & $5.34 \mathrm{~b}$ & $5.26 \mathrm{ab}$ & $1805 \mathrm{c}$ & $1628 \mathrm{~b}$ \\
\hline $60 \% \mathrm{CF}+\mathrm{BF}_{2}$ & $1.86 \mathrm{c}$ & $1.67 \mathrm{~b}$ & $2.61 \mathrm{~b}$ & $3.07 \mathrm{~cd}$ & $3.63 \mathrm{a}$ & 3.64ab & $5.68 \mathrm{~b}$ & $5.37 \mathrm{a}$ & $1904 \mathrm{c}$ & $1714 \mathrm{~b}$ \\
\hline $80 \% \mathrm{CF}+\mathrm{OF}_{3}+\mathrm{BF}_{3}$ & $2.04 \mathrm{~b}$ & $1.61 \mathrm{~b}$ & $2.73 b$ & $2.65 \mathrm{de}$ & $3.77 \mathrm{a}$ & $3.75 \mathrm{a}$ & $6.34 \mathrm{a}$ & $5.51 \mathrm{a}$ & $2079 b$ & $1638 \mathrm{~b}$ \\
\hline $60 \% \mathrm{CF}+\mathrm{OF}_{4}+\mathrm{BF}_{4}$ & $2.18 \mathrm{a}$ & $1.87 \mathrm{a}$ & $2.46 \mathrm{~b}$ & $2.17 \mathrm{f}$ & $3.71 \mathrm{a}$ & $3.81 \mathrm{a}$ & $6.44 \mathrm{a}$ & $5.54 \mathrm{a}$ & $2218 \mathrm{a}$ & $1914 \mathrm{a}$ \\
\hline
\end{tabular}

表中所列数据为平均值,每一列中不同字母表示在 0.05 水平上差异显著; $\mathrm{CK}$ 表示不施肥对照; $\mathrm{CF}$ : 灌耕灰漠土(灌淤旱耕人为土) Conventional fertilization; $80 \%$ $\mathrm{CF}+\mathrm{OF}_{1}: 80 \% \mathrm{CF}+$ 有机肥 $3000 \mathrm{~kg} / \mathrm{hm}^{2} ; 60 \% \mathrm{CF}+\mathrm{OF}_{2}: 60 \% \mathrm{CF}+$ 有机肥 $6000 \mathrm{~kg} / \mathrm{hm}^{2} ; 80 \% \mathrm{CF}+\mathrm{BF}_{1}: 80 \% \mathrm{CF}+$ 生物有机肥 $3000 \mathrm{~kg} / \mathrm{hm}{ }^{2} ; 60 \% \mathrm{CF}+\mathrm{BF}{ }_{2}: 60 \% \mathrm{CF}+$ 生物有机肥 $6000 \mathrm{~kg} / \mathrm{hm}^{2} ; 80 \% \mathrm{CF}+\mathrm{OF}_{3}+\mathrm{BF}_{3}: 80 \% \mathrm{CF}+$ 有机肥 $2250 \mathrm{~kg} / \mathrm{hm}^{2}+$ 生物有机肥 $750 \mathrm{~kg} / \mathrm{hm}^{2} ; 60 \% \mathrm{CF}+\mathrm{OF}_{4}+\mathrm{BF}_{4}: 60 \% \mathrm{CF}+$ 有机肥 $4500 \mathrm{~kg} / \mathrm{hm}{ }^{2}+$ 生物有机肥 $1500 \mathrm{~kg} / \mathrm{hm}{ }^{2}$ 
2.3 有机无机肥对土壤微生物数量比的影响

通过土壤不同种类微生物数量比值可反映不同 施肥处理对农田土壤微生物群落组成结构的影响。 由图 2 可知,蕾期 $\mathrm{CF}$ 处理显著降低了土壤细菌/真 菌比,而施用有机肥或生物有机肥则能显著提高土 壤细菌/真菌比, 并且随着施用量的增加而升高, 在 蕾期和铃期均有相同表现趋势。有机配施处理间蕾 期和铃期细菌数量均表现为 $\mathrm{OF}+\mathrm{BF}>\mathrm{BF}>\mathrm{OF}$, 同类有 机肥配施不等量化学肥料差异不显著。其中蕾期, 施用 $3000 \mathrm{~kg} / \mathrm{hm}^{2}$ 和 $6000 \mathrm{~kg} / \mathrm{hm}^{2}$ 有机肥或生物有机 肥处理的细菌/真菌比值分别较 $\mathrm{CF}$ 处理的增加了 1.1 和 1.6 倍。不同有机肥配施处理间的细菌/真菌
比值以 $60 \% \mathrm{CF}+\mathrm{OF}_{4}+\mathrm{BF}_{4}$ 处理最大, 其它不同处理对 细菌/真菌比的影响无明显差异。土壤放线菌/真菌 和假单胞杆菌/真菌比值对施肥各处理的响应特点 与施肥处理对细菌/真菌比值的影响相似 (图 2)。 表明施用有机肥或生物有机肥可改变滴灌棉田细 菌、真菌、放线菌等群落的组成结构, 提高细菌在土 壤微生物群落的所占比例。施用化肥或有机肥均显 著降低了假单胞杆菌/细菌比, 其中蕾期施用 3000 $\mathrm{kg} / \mathrm{hm}^{2}$ 和 $6000 \mathrm{~kg} / \mathrm{hm}^{2}$ 有机类肥料的假单胞杆菌/细 菌较 CF 处理降低了 $19.1 \%$ 和 $16.7 \%$ 。说明增施有 机肥可改变土壤细菌的群落结构, 降低假单胞杆菌 在细菌群落中所占的比例。
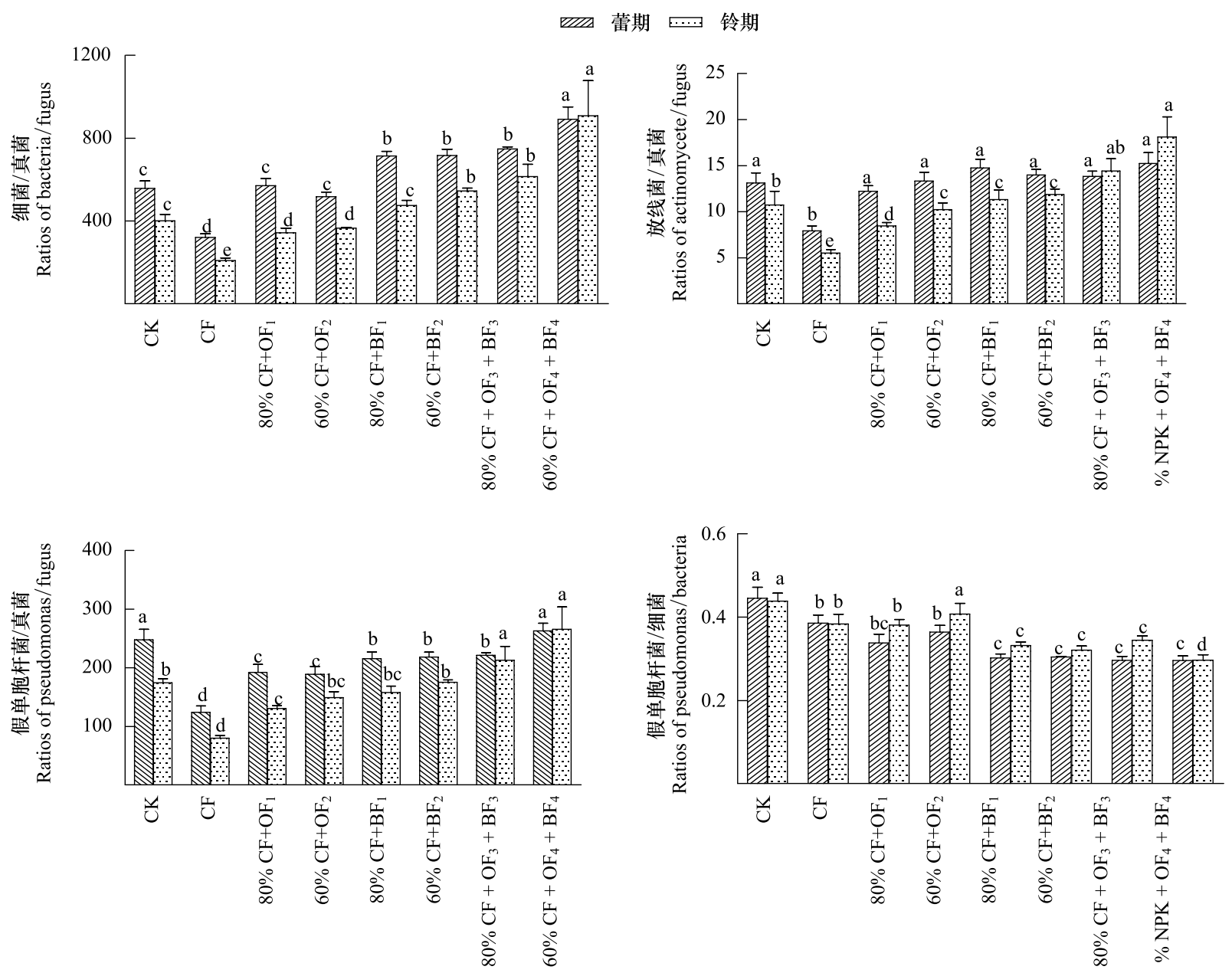

图 2 有机无机肥配施对细菌/真菌、放线菌/真菌、假单胞杆菌/真菌和假单胞杆菌/细菌的数量比

Fig.2 The influence of organic manure combined with chemical fertilizers on quantity ratios of bacteria/fungi, actinomycetes/fungi, pseudomonadaceae/fungi and pseudomonadaceae/bacteria

2.4 有机无机肥配施对土壤土壤酶活性的影响 土壤碱性磷酸酶、苂光素二乙酸酯酶 $(3,6-二 乙$
酰苂光素，FDA）、 $\beta$-葡萄糖苷酶和脱氢酶是土壤有 机碳降解和养分转化的关键酶, 其活性常被表征土 
壤微生物活性。由图 3 可知, 有机无机肥配施各处 理均显著增强了碱性磷酸酶、苂光素二乙酸酯酶、土 壤脱氢酶、 $\beta$-葡萄糖苷酶 4 种酶的活性, 尤其是土壤 脱氢酶活性。相较 $\mathrm{CF}$, 有机无机肥配施处理碱性磷 酸酶活性增强了 $0.1 \%-12.9 \%$,并且随着有机肥施 人量的增加而增加, 配施等量化学肥料, 碱性磷酸酶 活性表现为 $\mathrm{OF}+\mathrm{BF}>\mathrm{BF}>\mathrm{OF}$ 。表明增施有机肥可显 著增加碱性磷酸酶活性, 但有机肥与生物有机肥处 理间无明显差异。苂光素二乙酸酯酶、 $\beta$-葡萄糖苷 酶与碱性磷酸酶活性有相似的趋势。相较于 CK 和 $\mathrm{CF}$ 处理,有机无机配施处理对土壤脱氢酶活性影响 较大, 分别增强了 $1.2-1.9$ 和 $1.0-1.6$ 倍, 有机配 施间 $80 \% \mathrm{CF}+\mathrm{BF}$ 脱氢酶活性略低于其他处理。

2.5 土壤微生物数量与酶活性的影响 土壤微生物是土壤酶的主要来源之一, 因此土
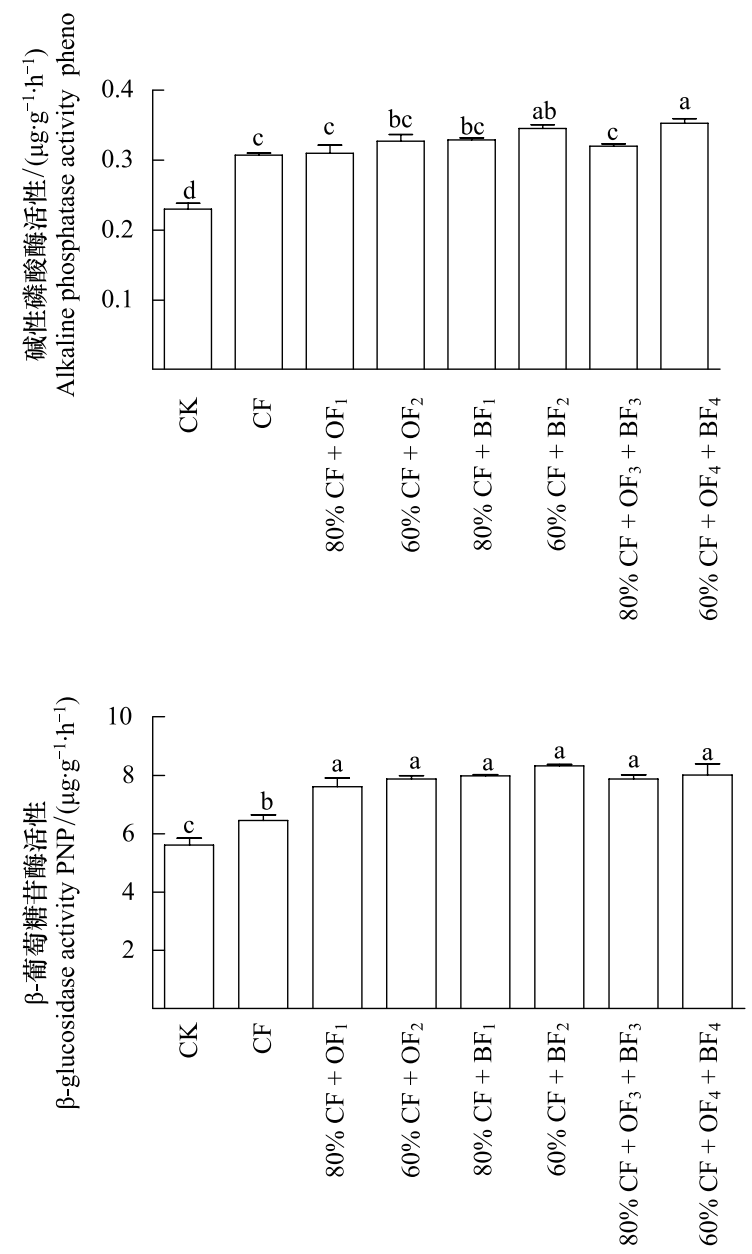

壤微生物数量与土壤酶密切相关。表 2 中细菌数量 与土壤脱氢酶、 $\beta$-葡萄糖苷酶、碱性磷酸酯酶和苂光 素二乙酸酯酶活性均呈显著或极显著正相关 $(P<$ $0.05)$, 说明细菌对这 4 种酶活性均有显著的促进作 用,根据 $Y=K x+b$ 线性拟合回归方程的斜率 $K$ 可知, 土壤酶活性对细菌数量反应大小表现为: $\beta$-葡萄糖 苷酶 $>$ 脱氢 酶 $>$ 碱性磷酸酶 $\approx$ 苂光素二乙酸酯酶活 性。放线菌和假单胞杆菌与以上 4 种酶活性也呈正 相关,各酶活对放线菌和假单胞杆菌反应大小顺序 均为 $\beta$-葡萄糖苷酶 $>$ 脱氢酶>苂光素二乙酸酯酶>碱 性磷酸酶活性。4 种酶活性与真菌数量是负相关关 系,通过其与酶活性拟合方程的斜率可以看出真菌 数量对苂光素二乙酸酯酶和碱性磷酸酶活性影响较 弱, 而与 $\beta$-葡萄糖苷酶、脱氢酶活性呈显著和极显著 负相关。
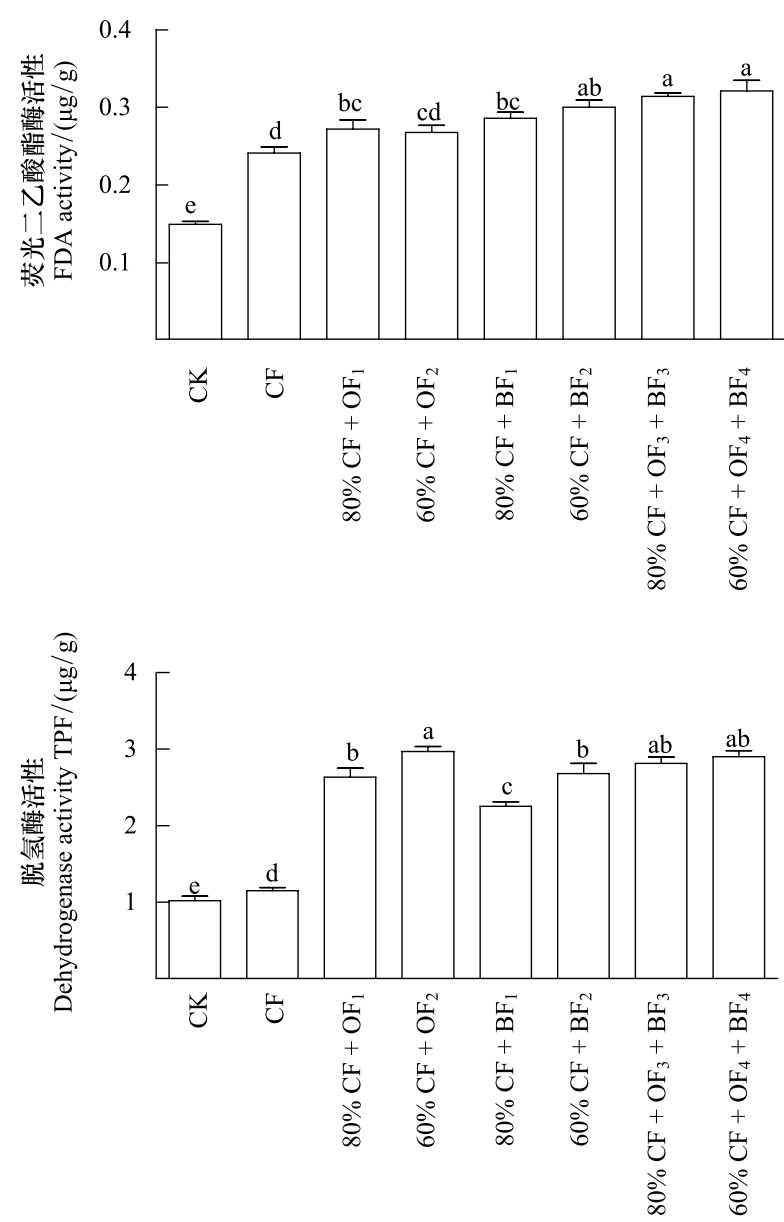

图 3 有机无机肥配施对碱性磷酸酶、FDA、 $\beta$-葡萄糖苷酶和脱氢酶活性的影响

Fig.3 The influence of organic manure combined with chemical fertilizers on activities of alkaline phosphates, FDA, $\beta$-glucosidase and dehydrogenase in soils 
表 2 碱性磷酸酶、FDA、 $\boldsymbol{\beta}$-葡萄糖苷酶、脱氢酶活性与细菌、真菌、放线菌和假单胞杆菌数量的线型回归

Table 2 Liner correlation equations between quantities of soil bacteria, fungi, actinomycetes, pseudomonas and the activities of alkaline phosphatase, FDA, $\beta$-glucosidase and dehydrogenase

\begin{tabular}{|c|c|c|c|c|}
\hline \multirow[t]{2}{*}{$\begin{array}{l}\text { 微生物数量/cfu/g(干土) } \\
\text { Quantities of soil microorganism }\end{array}$} & \multirow[b]{2}{*}{$\beta$-葡萄糖苷酶 } & \multirow{2}{*}{$\begin{array}{l}\begin{array}{l}\text { 拟合方程 } \\
\text { Fitting equation }\end{array} \\
y_{1}=2.7155 x+3.5494\end{array}$} & \multicolumn{2}{|c|}{$\begin{array}{c}\text { 相关系数 } \\
\text { Correlation coefficient }\end{array}$} \\
\hline & & & $R^{2}=0.7059$ & $0.84^{* *}$ \\
\hline 细菌数量 & 脱氢酶 & $y_{2}=2.0037 x-0.5873$ & $R^{2}=0.5479$ & $0.74^{*}$ \\
\hline Quantities of Bacteria $\times 10^{7} /$ & 碱性磷酸酶 & $y_{3}=0.1093 x+0.1577$ & $R^{2}=0.7009$ & $0.837^{* *}$ \\
\hline \multirow{2}{*}{$\mathrm{cfu} / \mathrm{g}$ (干土) } & FDA & $y_{4}=0.1685 x+0.026$ & $R^{2}=0.7876$ & $0.887^{* *}$ \\
\hline & $\beta$-葡萄糖苷酶 & $y_{1}=-0.5714 x+9.5626$ & $R^{2}=0.5581$ & $-0.747^{*}$ \\
\hline 真菌数量 & 脱氢酶 & $y_{2}=-0.5292 x+4.2446$ & $R^{2}=0.6824$ & $-0.826 * *$ \\
\hline Quantities of Fungus $\times 10^{5} /$ & 碱性磷酸酶 & $y_{3}=-0.0305 x+0.3807$ & $R^{2}=0.4595$ & $-0.678^{*}$ \\
\hline \multirow[t]{2}{*}{$\mathrm{cfu} / \mathrm{g}$ (干土) } & FDA & $y_{4}=-0.0171 x+0.378$ & $R^{2}=0.3064$ & -0.553 \\
\hline & $\beta$-葡萄糖苷酶 & $y_{1}=2.165 x-0.0082$ & $R^{2}=0.89$ & $0.943^{* *}$ \\
\hline 放线菌数量 & 脱氢酶 & $y_{2}=1.6552 x-3.4115$ & $R^{2}=0.7416$ & $0.861^{* *}$ \\
\hline Quantities of Actinomycete $\times 10^{5} /$ & 碱性磷酸酶 & $y_{3}=0.0829 x+0.0291$ & $R^{2}=0.7998$ & $0.894^{* *}$ \\
\hline \multirow[t]{2}{*}{$\mathrm{cfu} / \mathrm{g}$ (干土) } & FDA & $y_{4}=0.125 x-0.1627$ & $R^{2}=0.8605$ & $0.928 * *$ \\
\hline & $\beta$-葡萄糖苷酶 & $y_{1}=1.9215 x-2.3465$ & $R^{2}=0.8637$ & $0.929^{* *}$ \\
\hline 假单胞杆菌数量 & 脱氢酶 & $y_{2}=1.6358 x-6.0506$ & $R^{2}=0.8924$ & $0.945^{* *}$ \\
\hline Quantities of Pseudomonas $\times 10^{6} /$ & 碱性磷酸酶 & $y_{3}=0.1066 x-0.2754$ & $R^{2}=0.7706$ & $0.878^{* *}$ \\
\hline $\mathrm{cfu} / \mathrm{g}$ (干土) & FDA & $y_{4}=0.0662 x-0.0228$ & $R^{2}=0.6286$ & $0.793 *$ \\
\hline
\end{tabular}

$* *$ : 在 0.01 水平上差异显著; $*$ : 在 0.05 水平上差异显著

\section{3 讨论}

本研究表明,减少 $20-40 \%$ 当地常规化肥施用 量情况下,配施 $3000 、 6000 \mathrm{~kg} / \mathrm{hm}^{2}$ 有机肥或生物有 机肥不但可使棉花产量达到与完全施用化肥相同的 效果,而且施用有机肥或生物有机肥对滴灌条件下 长期连作棉田土壤微生物数量和酶活性产生了显著 的影响。从有机肥对土壤微生物群落组成结构、微 生物数量与酶活性等方面的影响分析, 有机肥和生 物有机肥含丰富有机碳源 ${ }^{[22]}$, 对提高土壤微生物数 量、酶活性及驱动微生物群落组成结构方面发挥着 显著作用。李秀英等 ${ }^{[23]}$ 在国家长期肥料定位试验 站褐潮土上的试验研究表明与单施化肥处理相比, 化肥配施有机肥或秸秆可明显提高土壤中细菌和真 菌数量, 放线菌数量周年平均增加可达 $24.2 \%$; 李忠 佩等 ${ }^{[24]}$ 研究表明,由于秸秆还田、根茬、施用有机肥 等大量有机物归还,耕作 $30 \mathrm{a}$ 和 $80 \mathrm{a}$ 土壤 $0-10 \mathrm{~cm}$ 、 $10-20 \mathrm{~cm}$ 土层细菌数量分别比耕作 $3 \mathrm{a}$ 的增加了 1.11 和 3.8 倍与 19 和 12 倍; 钱海燕等 ${ }^{[25]}$ 研究也表 明秸秆还田配施化肥及微生物菌剂刺激了微生物的 生长和活动, 细菌与真菌数量显著高于对照处理 (CK), 本研究中有机无机肥配施特别是配施生物有
机肥显著降低土壤真菌数量, 与 $\mathrm{Nanda}^{[26]}$ 在连续施 用有机无机肥肥配施对土壤微生物数量的研究结果 相同,但李秀英等 ${ }^{[23]}$ 的实验则表明有机无机肥配施 会提高真菌数量, 其原因可能与施人的有机肥类型 以及施肥模式有关, 特别是施人生物有机肥中含有 大量的功能菌, 对真菌土传病菌生长有抑制作用。 本研究发现不同施肥处理不但改变了细菌、真菌、放 线菌和假单胞杆菌的数量, 而且对土壤微生物群落 结构也有影响, 如有机无机肥配施能显著增加土壤 细菌/真菌、放线菌/真菌和假单胞杆菌/真菌的比 值, 这与刘杏兰等 ${ }^{[27]}$ 和孙瑞莲等 ${ }^{[28]}$ 的研究一致。因 此有机肥在土壤中的作用不仅仅是提供营养, 它在 优化调控土壤细菌、真菌等微生物群落区系结构, 促 进根际土壤 PGPR 菌,进而提高作物产量等方面的 作用更应该引起重视 ${ }^{[29-30]}$ 。

土壤酶主要来源于土壤微生物, 其活性与土壤 微生物的数量和群落结构有密切关系。张向前 等 ${ }^{[31]}$ 在对间作玉米土壤微生物数量和酶活性研究 中发现细菌、真菌和放线菌对土壤酶有正向促进作 用,顾美英 ${ }^{[32]}$ 对新疆棉田微生物研究亦发现细菌数 量和土壤酶活性有一定的相关性,而放线菌和真菌 与土壤酶无显著相关性。从本研究结果分析来看, 
虽然与化肥处理相比, 有机无机肥配施处理能显著 提高 4 种酶活性,但是碱性磷酸酶、荧光素二乙酸酯 酶、 $\beta$-葡萄糖苷酶 3 种酶活性在有机无机肥配施处 理之间的差异并不显著,即有机肥与生物有机肥之 间对以上 3 种酶活性的作用并无明显差异。而且在 本研究发现,细菌和放线菌与碱性磷酸酶、苂光素二 乙酸酯酶、 $\beta$-葡萄糖苷酶和脱氢酶 4 种土壤酶活性 都呈显著正相关, 但真菌与 4 种酶活性却表现为一 定的负相关, 这和孙秀山 ${ }^{[33]}$ 与赵萌 ${ }^{[34]}$ 分别对花生和 西瓜的连作研究发现真菌数量和部分土壤酶负相关 相符,其原因可能与作物的类型和耕作模式以及施 用化肥导致土壤 $\mathrm{pH}$ 值变化抑制了部分酶活性有关。 长期棉花连作导致枯、黄萎病真菌类致病菌土传病 害是影响新疆植棉区棉花产量的主要因素,通过生 物有机无机复合肥中的大量有机物质和有益微生物 共同作用,促进土壤微生物数量升高, 改善土壤微生 物组成比例, 提高土壤微生物种群数量多样性土壤 酶活性,这可能是新疆绿洲长期连作棉田有机类肥 料能部分替代化肥, 提高养分资源高效利用及高农 田土壤生产力的重要途径与技术措施。

\section{4 结论}

(1) 在新疆北疆棉区,施用 $3000 、 6000 \mathrm{~kg} / \mathrm{hm}^{2}$ 的有机或生物有机肥, 替代 $20 \%-40 \%$ 常规化肥用 量可保证棉花正常生长, 并达到与单施化肥处理相 同产量。

(2) 有机无机肥配施可明显改善土壤生物活 性, 与 $\mathrm{CF}$ 相比,施用 $3000 、 6000 \mathrm{~kg} / \mathrm{hm}^{2}$ 有机肥和生 物有机肥处理的 $\beta$-葡萄糖苷酶和脱氢酶分别提高了 $0.2-0.3$ 和 $1.0-1.6$ 倍, 并能显著提高土壤碱性磷 酸酶、苂光素二乙酸酯酶活性。

（3）有机无机肥配施可明显增加棉田土壤细 菌、放线菌和假单胞杆菌数量, 抑制真菌的生长。增 施有机肥可显著提高细菌/真菌、放线菌/真菌、假单 胞杆菌/真菌, 降低假单胞杆菌/细菌的比值, 通过有 机无机肥配施可达到调控土壤微生物区系组成结构 比例的目的。

\section{References :}

[ 1 ] Stewart W M. Contribution of fertilizer to crop yield. Xie L Translated. Agrochemical Science and Technology, 2003, (3) : 31-33.
[ 2 ] Shi Y L, Wang L L, Liu S B, Nie H G. Development of chemical fertilizer industry and its effect on agriculture of China. Acta Pedologica Sinica, 2008, 45(5) : 852-864.

[ 3 ] Shen Q R, Tan J F, Qian X Q. An Introduction to Soil and Fertilizer. Beijing: Higher Education Press, 2001: 4-6, 270-271.

[ 4 ] Wang J F, Xing S Z. Negative effects of application chemical fertilizers on farmland and the control measures.. AgroEnvironmental Protection, 1998, 17(1): 40-43.

[ 5 ] Roelck M, Han Y, Schleef K H, Zhu J G, Liu G, Cai Z C, Richter J. Recent trends and recommendations for nitrogen fertilization in intensive agriculture in eastern China. Pedosphere, $2004,14(4): 449-460$.

[6] Liu H, Lin Y H, Zhang Y S, Tan X X, Wang X H. Effects of long-term fertilization on Biodiversity and enzyme activity in grey desert soil. Acta Ecologica Siaica, 2008, 28(8) : 3898-3904

[ 7 ] Shen Q R, Wu J. National readjustment and control is needed to develop the organic fertilizer industry. Visit the national organic fertilizer professional committee of Nanjing agricultural university, director of vice President Shen Qirong doctoral tutor. The Chinese Cooperation Times, 2009-6-12 ( 14 ).http://www.fert. cn/news/ 2009/6/12/200961217151286582.shtml.

[8] He X Y, Hao M D, Li H C, Cai Z F. Effects of different fertilization on yield of wheat and water and fertilizer use efficiency in the Loess Plateau. Plant Nutrition and Fertilizer Science, 2010, $16(6)$ : $1333-1340$

[ 9 ] Lin X J, Wang F, Cai H S, Lin R B, He C M, Li Q H, Li Y. Effects of different organic fertilizers on soil microbial BFmass and yield of peanut. Chinese Journal of Eco-Agriculture, 2009, 17 (2) : 235-238.

[10] Liu G R, Feng Z B, Liu X M, Chen X M, Zou S W, Li Z Z, Zhou W. Effects of different manure sources on soil characters in upland red soil. Acta Agriculturae Universitatis Jiangxiensis, 2009, 31(5) : 927-932, 938-938.

[11 ] Plaza C, Hernandez D, Garcia-Gil J C, Polo A. Microbial activity in pig slurry-amended soils under semiarid conditions. Soil Biology and Biochemistry, 2004, 36(10): 1577-1585.

[12] Kautz T, Wirth S, Ellmer F. Microbial activity in a sandy arable soil is governed by the fertilization regime. European Journal of Soil Biology, 2004, 40(2) : 87-94.

[13] Janvier C, Villeneuve F, Alabouvette C, Edel-Hermann V, Mateille T, Steinberg C. Soil health through soil disease suppression: Which strategy from descriptors to indicators. Soil Biology and Biochemistry, 2007, 39(1): 1-23.

[14] Yang X M, Xu Y C, Huang Q W, Xu M, Liang R H, Hu J, Ran W, Shen Q R. Organic-like fertilizers and its relation to sustainable development of agriculture and protection of ecoenvironment. Acta Pedologica Sinica, 2008, 45(5) : 925-32.

[15] Chen F, Xiao T J, Zhu Z, Yang X M, Ran W, Shen Q R. Effect of Bio-organic fertilizers on root-knot nematode of muskmelon in 
field. Plant Nutrition and Fertilizer Science, 2011, 17 ( 5 ): 1262- 1267 .

[16] Hu X T, Li M S. Effect of trickle irrigation under sub-film on the soil conditions of rhizosphere in cotton. Chinese Journal of EcoAgriculture, 2003, 11(3): 121-123.

[17] Shi L Y. The analysis of Cotton verticillium wilt disasters factors. China Cotton, 1999, 26(7) : 8-9.

[18] Perez-Piqueres A, Edel-Hermann V, Alabouvette C, Steinberg C. Response of soil microbial communities to compost amendments. Soil Biology and Biochemistry, 2006, 38(3) : 460-470.

[19] Pankhurst C E, McDonald H J, Hawke B G, Kirkby C A. Effect of tillage and stubble management on chemical and microBiological properties and the development of suppression towards cereal root disease in soils from two sites in NSW, Australia. Soil Biology and Biochemistry, 2002, 34(6): 833-840.

[20] Sigler W V, Nakatsu C H, Reicher Z J, Turco R F. Fate of the biological control agent pseudomonas aureofaciens TX-1 after application to turfgrass. Applied and Environmental Microbiology, $2001,67(8): 3542-3548$.

[21] Li Z G, Luo Y M, Teng Y. The Research of Soil and Environmental Microbial. Beijing: Science Press, 2008: 395-417.

[22] $\mathrm{Li} \mathrm{D} \mathrm{P,} \mathrm{Wu} \mathrm{Z} \mathrm{J,} \mathrm{Chen} \mathrm{L} \mathrm{J.} \mathrm{Influence} \mathrm{of} \mathrm{fertilizing} \mathrm{modes} \mathrm{of}$ organic agriculture on the soil microbial activities. Chinese Journal of Eco-Agriculture, 2005, 13(2) : 99-101.

[23] Li X Y, Zhao B Q, Li X H, Li Y T, Sun R L, Zhu L S, Xu J, Wang L X, Li X P, Zhang F D. Effects of different fertilization systems on soil microbe and its relation to soil fertility. Scientia Agricultura Sinica, 2005, 38(8) : 1591-1599

[24] Li Z P, Zhang T L, Chen B Y, Yi R L, Shi Y Q. Soil organic matter dynamics in a cultivation chronosequence of paddy fields in subtropical China. Acta Pedologica Sinca, 2003, 40 ( 3 ): 344-352.

[25] Qian H Y, Yang B J, Huang G Q, Yang Y P, Fan Z, Fang Y. Effects of returning rice straw to fields with fertilizers and microorganism liquids on soil enzyme activities and microorganisms in paddy fields. Ecology and Environmental Sciences, 2012, 21 (3) : 440-445.

[26] Nanda S K, Das P K, Behera B. Effects of continuous manuring on microbial population, ammonification and $\mathrm{CO}_{2}$ evolution in a rice soil. Oryza, 1998, 25(4) : 413-416.

[27] Liu X L, Gao Z, Liu C S, Si L Z. Effect of combined application of organic manure and fertilizers on crop yield and soil fertility in a located experiment. Acta Pedologica Sinica, 1996, 33 ( 2 ) 138- 147.

[28] Sun R L, Zhu L S, Zhao B Q, Zhou Q X, Xu J, Zhang F D. Effects of long-term fertilization on soil microorganism and its role in adjusting and controlling soil fertility. Chinese Journal of Applied Ecology, 2004, 15(10): 1907-1910

[29] Kong W D, Liu K X, Liao Z W. Effects of different organic materials and their composting levels on soil microbial community. Chinese Journal of Applied Ecology, 2004, 15(3) : 487-4921.

[30 ] Tan Z Z, Liu K X, Liao Z W. The effect of BHA on soil microbial diversity and controlling bacterial wilt of tomato. Humic Acid, 2005 , (6) : 23-27.

[31] Zhang X Q, Huang G Q, Bian X M, Jiang X H, Zhao Q G. Effects of intercropping on quality and yield of maize grain, microorganism quantity, and enzyme activities in soils. Acta Ecologica Sinica, 2012, 32(22) : 7082-7090.

[32] Gu M Y, Xu W L, Mao J, Liang Z, Zhang J D, Fang S J. Effects of cotton continuous cropping on the amount of soil microbes and enzyme activities in Xinjiang. Agricultural Research in the Arid Areas, 2009, 27(1): 1-5.

[33] Sun X S, Feng H S, Wan S B, Zuo X Q. Changes of main microbial strains and enzymes activities in peanut continuous cropping soil and their interactions. Acta Agronomica Sinica, $2001,27(5): 617-621$

[34] Zhao M, Li M, Wang M Y, Wang Y, Zhang X Y. Effects of watermelon replanting on main microflora of rhizosphere and activities of soil enzymes. Microbiology, 2008, 35 ( 8 ): $1251-1254$.

\section{参考文献:}

[ 1 ] Stewart W M. 肥料对作物产量的贡献. 谢玲译. 农资科技， 2003 , (3) : 31-33.

[2] 石元亮, 王玲莉, 刘世涁, 聂鸿光. 中国化学肥料发展及其对 农业的作用. 土壤学报, 2008, 45(5)：852-864.

[3] 沈其荣, 谭金芳, 钱晓晴. 土壤肥料学通论. 北京: 高等教育 出版社, 2001: 4-6, 270-271.

[4] 汪建飞, 邢素芝. 农田土壤施用化肥的负效应及其防治对策. 农业环境保护，1998，17(1)：40-43。

［6］刘骅, 林英华, 张云舒, 谭新霞, 王西和. 长期施肥对灰漠土 生物群落和酶活性的影响. 生态学报, 2008, 28 ( 8): 3898-3904.

[ 7 ] 沈其荣, 吴江. 发展有机肥行业需要国家层面引导一一访全 国有机肥专业委员会主任、南京农业大学副校长、博士生导师 沈其荣. 中华合作时报，2009-6-12 (14). http://www.fert.cn/ news/2009/6/12/200961217151286582.shtml.

［8］何晓雁, 郝明德, 李慧成, 蔡志风. 黄土高原旱地小麦施肥对 产量及水肥利用效率的影响. 植物营养与肥料学报, 2010, 16 (6) : 1333-1340.

[9] 林新坚, 王飞, 蔡海松, 林戎斌, 何春梅, 李清华, 李昱. 不 同有机肥源对土壤微生物生物量及花生产量的影响. 中国生 态农业学报, 2009, 17(2)：235-238.

[10］刘光荣，冯兆滨，刘秀梅，陈先茂，邹绍文，李祖章，周卫. 不同有机肥源对红壤旱地耕层土壤性质的影响. 江西农业大 学学报, 2009, 31(5): 927-932, 938-938.

[14] 杨兴明, 徐阳春, 黄启为, 徐茂, 梁永红, 胡江, 再炜, 沈其 荣. 有机 (类)肥料与农业可持续发展和生态环境保护. 土壤 
学报, 2008, 45(5): 925-32.

[15]陈芳, 肖同建, 朱震, 杨兴明, 再炜, 沈其荣. 生物有机肥对 甜瓜根结线虫病的田间防治效果研究. 植物营养与肥料学报, $2011,17(5)$ : 1262-1267.

[16] 胡晓棠, 李明思. 膜下滴灌对棉花根际土壤环境的影响研究. 中国生态农业学报, 2003, 11(3): 121-123.

[17] 石否岩. 棉花黄萎病灾害因素分析. 中国棉花, 1999, 26(7): 8-9.

[21］李振高, 骆永明, 滕应. 土壤与环境微生物研究法. 北京: 科 学出版社, 2008: 395-417.

[22] 李东坡, 武志杰, 陈利军. 有机农业施肥方式对土壤微生物活 性的影响研究. 中国生态农业学报, 2005, 13(2)：99-101.

[23] 李秀英, 赵秉强, 李絮花, 李燕婷, 孙瑞莲, 朱鲁生, 徐晶, 王丽霞, 李小平, 张夫道. 不同施肥制度对土壤微生物的影响 及其与土壤肥力的关系. 中国农业科学, 2005, 38(8): 1591-1599.

[24] 李忠佩, 张桃林, 陈碧云, 尹瑞龄, 施亚琴. 红壤稻田土壤有 机质的积累过程特征分析. 土壤学报, 2003, 40(3) : 344-352.

[25] 钱海燕, 杨滨娟, 黄国勤, 严玉平, 焚哲, 方豫. 秸秆还田配 施化肥及微生物菌剂对水田土壤酶活性和微生物数量的影 响. 生态环境学报, 2012, 21(3): 440-445.

［27］刘杏兰, 高宗, 刘存寿, 司立征. 有机-无机肥配施的增产效
应及对土壤肥力影响的定位研究. 土壤学报, 1996, 33(2)： 138- 147 .

[28] 孙瑞莲, 朱鲁生, 赵秉强, 周启星, 徐晶, 张夫道. 长期施肥 对土壤微生物的影响及其在养分调控中的作用. 应用生态学 报, 2004, 15(10) : 1907-1910.

[29］孔维栋, 刘可星, 廖宗文. 有机物料种类及腐熟水平对土壤微 生物群落的影响. 应用生态学报, 2004, 15(3) : 487-492.

[30］谭兆赞, 刘可星, 廖宗文. 生化腐植酸对土壤微生物多样性及 番茄青枯病的影响. 腐植酸, 2005, (6) : 23-271.

［31］张向前, 黄国勤，市新民，江学海，赵其国. 间作对玉米品质、 产量及土壤微生物数量和酶活性的影响. 生态学报, 2012, 32 (22) : 7082-7090.

[32] 顾美英, 徐万里, 范军, 梁智, 张志东, 房世杰. 连作对新疆 绿洲棉田土壤微生物数量及酶活性的影响. 干旱地区农业研 究, 2009, 27(1) : 1-5

[33] 孙秀山, 封海胜, 万书波, 左学青. 连作花生田主要微生物类 群与土壤酶活性变化及其交互作用. 作物学报, 2001, 27 (5) : 617-621.

[34] 赵萌, 李敏, 王氷炎, 王玉, 张学义. 西瓜连作对土壤主要微 生物类群和土壤酶活性的影响. 微生物学通报, 2008, 35 (8) : 1251-1254. 